\title{
Longitudinal analysis of sleep in relation to BMl and body fat in children: the FLAME study
}

\author{
PhilippaJ Carter, doctoral student, ${ }^{1}$ Barry J Taylor, professor, head of department, ${ }^{1}$ Sheila M Williams, research \\ associate professor, biostatistician, ${ }^{2}$ Rachael W Taylor, Karitane research associate professor in early \\ childhood obesity ${ }^{3}$
}

\section{'Department of Women's and Children's Health, University of Otago, Dunedin, New Zealand ${ }^{2}$ Department of Preventive and Social Medicine, University of Otago \\ ${ }^{3}$ Edgar National Centre for Diabetes and Obesity Research, Department of Medical and Surgical Sciences, University of Otago}

Correspondence: R Taylor, Department of Human Nutrition, PO Box 56, Dunedin 9054, New Zealand

rachael.taylor@otago.ac.nz

Cite this as: BMJ 2011;342:d2712 doi:10.1136/bmj.d2712

\section{ABSTRACT}

Objectives To determine whether reduced sleep is associated with differences in body composition and the risk of becoming overweight in young children.

Design Longitudinal study with repeated annual measurements.

Setting Dunedin, New Zealand.

Participants 244 children recruited from a birth cohort and followed from age 3 to 7 .

Main outcome measures Body mass index (BMI), fat mass $(\mathrm{kg})$, and fat free mass $(\mathrm{kg})$ measured with bioelectrical impedance; dual energy $x$ ray absorptiometry; physical activity and sleep duration measured with accelerometry; dietary intake (fruit and vegetables, non-core foods), television viewing, and family factors (maternal BMI and education, birth weight, smoking during pregnancy) measured with questionnaire.

Results After adjustment for multiple confounders, each additional hour of sleep at ages 3-5 was associated with a reduction in $\mathrm{BMI}$ of 0.48 ( $95 \%$ confidence interval 0.01 to 0.96 ) and a reduced risk of being overweight (BMI $\geq 85$ th centile) of 0.39 ( 0.24 to 0.63 ) at age 7 . Further adjustment for BMI at age 3 strengthened these relations. These differences in BMI were explained by differences in fat mass index $(-0.43,-0.82$ to -0.03$)$ more than by differences in fat free mass index $(-0.21,-0.41$ to -0.00$)$. Conclusions Young children who do not get enough sleep are at increased risk of becoming overweight, even after adjustment for initial weight status and multiple confounding factors. This weight gain is a result of increased fat deposition in both sexes rather than additional accumulation of fat free mass.

\section{INTRODUCTION}

Despite recent data suggesting that the dramatic increases in overweight and obesity in children and adolescents seen over the past three decades have begun to plateau, rates remain alarmingly high. ${ }^{1-3}$ Concurrent with these increases has been a reduction in how long children sleep, ${ }^{45}$ raising the question of a link. ${ }^{6}$

Several recent reviews have now shown a relatively consistent relation between shorter sleep duration and increased risk of overweight in childhood, particularly in younger children. ${ }^{7-11}$ Most included studies were cross sectional, with eight recent prospective studies. ${ }^{12-19}$ While these studies offer interesting insights into the potential of sleep to influence body weight during growth, several questions remain. No longitudinal studies to date have used objective measures of sleep duration, ${ }^{10}$ which might be important given the questionable validity of parental reports of sleep in young children. ${ }^{8}$ In addition, sleep duration might not be stable over time, ${ }^{10}$ and only some studies have undertaken repeated observations. ${ }^{12}{ }^{15}$ 17-19 Given the myriad factors that have been implicated in the development of overweight, adjustment for important confounders - including parental size, physical activity, dietary intake, and particularly earlier weight status - is critical, yet has not always been undertaken.

To date, it is uncertain what changes in body composition (fat mass and fat free mass) accompany the increases in body weight observed with decreased sleep duration as virtually all studies have used body mass index (BMI) as the primary outcome. Determining how body composition differs in children with varying sleeping patterns could help to elucidate the mechanisms whereby sleep affects body composition. ${ }^{20}$ Although several cross sectional studies have shown that sleep is negatively associated with body fat, ${ }^{1721-24}$ the potential for reverse causality cannot be excluded. Furthermore, most studies have used skinfold estimates of body fat, ${ }^{1722-24}$ which might not be valid in individual children. ${ }^{25} \mathrm{We}$ determined the relation between serial measures of sleep and subsequent body composition in young children, obtained using objective measures of sleep duration and physical activity, adjusted for multiple confounders.

\section{METHODS}

Participants

The Family Lifestyle, Activity, Movement and Eating (FLAME) study is a longitudinal cohort observational study designed to examine factors in early childhood that could contribute to the development of overweight and obesity. The study has been described in full elsewhere. ${ }^{26}$ Briefly, children were recruited just before their 3rd birthday from a cohort born at 
Queen Mary Maternity Unit, Dunedin, the only maternity hospital serving the city of Dunedin, New Zealand. All children born between 19 July 2001 and 19 January 2002 and still living in Denedin were eligible. Children were excluded if they were premature $(<37$ completed weeks' gestation), one of a multiple birth, had major congenital abnormalities, if the mother had had severe postnatal illness, or if the family was unlikely to be living locally for the next two years. After exclusions, 413 children were eligible and 244 ( $44 \%$ girls) participated (59\% response rate). The children were white $(83 \%)$, with Maori (11\%), Pacific Islanders $(4 \%)$, and other ethnicities $(3 \%)$, reflecting the wider Otago population (Statistics New Zealand, 2001).

\section{Data collection}

Between the ages of 3 and 7 children were seen every six months at university research clinics. Data used in these analyses were obtained from the annual measures at ages 3 to 7 , inclusive. Measures of the main outcome variables - anthropometry and body composition (bioelectrical impedance) - were obtained every year. Diet and accelerometry (sleep and physical activity) were assessed only at ages 3,4 , and 5 . Because of potential limitations in the use of bioimpedance to assess body composition in young children, we also used dual energy $x$ ray absorptiometry (DXA) when the children were aged 5 and 7 . These scans were not considered suitable for children aged 3. Weight was measured twice in children (in light clothing and with shoes removed) with electronic scales (Toledo) to the nearest $0.1 \mathrm{~kg}$. Height was measured in duplicate to the nearest $0.1 \mathrm{~cm}$ with an electronic wall mounted stadiometer (Heightronic; QuickMedical, Northbend, WA). We measured body mass index (BMI) and calculated BMI z scores using reference data from the United States. ${ }^{27}$ Duplicate measures of body composition were obtained from bioelectrical impedance by using an RJL Quantum II Bioelectrical Impedance Analyzer (RJL Systems, Michigan) with standard procedures. Total body water was calculated as $1.291+0.411 \mathrm{H}^{2} /$ $\mathrm{R}+0.139 \mathrm{~W}+0.166 \mathrm{~A}-0.973$ (Tanner stage 1$)+0.641$ (male), where $\mathrm{H}^{2} / \mathrm{R}$ equals height $(\mathrm{cm})^{2} /$ resistance, $\mathrm{W}$ is weight (kg), and A is age (years), ${ }^{28}$ and converted to fat free mass (FFM) with age and sex specific hydration constant ${ }^{29}$ by using the equation $\mathrm{FFM}=\mathrm{TBW} /$ constant. Fat mass (FM) was calculated as weight $(\mathrm{kg})$ -FFM (kg). DXA (Lunar DPX-L scanner, software package 4.7, Lunar Corporation, Madison, WI) measures of body composition were also obtained at ages 5 and 7 by using standard procedures. ${ }^{30}$ We derived fat mass index (FMI, fat mass $\left.(\mathrm{kg}) / \mathrm{height}(\mathrm{m})^{2}\right)$ and fat free mass index (FFMI, fat free mass $(\mathrm{kg}) /$ height $\left.(\mathrm{m})^{2}\right)$ from these measures.

Sleep duration and physical activity were measured with Mini-Mitter (Bend, OR) omnidirectional Actical accelerometers attached by belts to the waist. ${ }^{31}$ Parents were instructed to keep the monitors on the children at all times for five consecutive days, including two weekend days. We chose time periods of 15 seconds to capture both low intensity and brief intermittent activity. ${ }^{32}$ Parents completed an activity log describing when the children went to bed, went to sleep, and woke up each day of measurement. Sleep duration was calculated by visual inspection of each individual actogram in conjunction with the parents' recorded activity logs. The potential sleep time included the period from the recorded bedtime to the rise time, as recommended by the American Academy of Sleep Medicine. ${ }^{33}$ The time of onset of sleep was defined as the first of three consecutive minutes in which there was no activity count over 50 for an individual minute after the reported bedtime. The end time was defined as the last of five consecutive minutes in which there was no activity count over 50 before the reported rise time. Sleep duration was the time from sleep onset to sleep end time. To allow for small inaccuracies in times reported by the parents, we also inspected the 30 minutes before the reported bedtime and after the rise time. Accelerometry activity counts were analysed for 24 hour periods and we used raw activity count data, expressed as mean count per minute, for analyses.

Parental weight and height were measured at baseline in all mothers and most (82\%) fathers. Estimates were obtained for the remaining fathers from measurements conducted at home (9\%) or provided from the child's mother $(9 \%)$. Maternal education, ethnicity, and income (which had six categories) were assessed with questions adapted from those used in the New Zealand Census (Statistics New Zealand, 2001). Birth weight was obtained from hospital records. Mothers reported whether they had smoked during the pregnancy and the average number of cigarettes a day, as well as the number of hours a day of television viewed by their child. ${ }^{26}$ Dietary intake was assessed over two weekdays and one weekend day at each time point (at ages 3,4 , and 5) with a validated short questionnaire that recalled the previous days' intake of food and drink. ${ }^{34}$ Food variables used in this analysis included fruit and vegetable intake and intake of non-core foods (sweet beverages, cakes and biscuits, sweets and chocolate, pies and pastries, pizza, and fast foods).

\section{Statistical analyses}

Cross sectional analyses-We used a mixed model with random effects for participant and age to examine the association between BMI and sleep at ages 3, 4, and 5 simultaneously. Other variables included in the models because of known associations with BMI in children were age, sex, maternal education and income, mother's BMI, birth weight, smoking in pregnancy, and ethnicity. We also included behavioural variables collected at ages 3,4 , and 5 (sleep, physical activity, television viewing, non-core food intake, and fruit and vegetable intake). Two variables were formed for the variables that were measured repeatedly over time; a "between person" effect or the average for each person, and a "within person" effect, using the difference between the observed values and the average value for each person. ${ }^{35}$ The average counts for physical activity 
Table 1 |Characteristics of children in study at each time point. Figures are means (SD) unless stated otherwise

\begin{tabular}{|c|c|c|c|c|c|}
\hline & \multicolumn{5}{|c|}{ Age (years) } \\
\hline & $3(n=244)$ & $4(n=236)$ & $5(n=2226)$ & $6(n=202)$ & $7(n=202)$ \\
\hline No (\%) female & $107(44)$ & $102(43)$ & $99(44)$ & $86(43)$ & $86(43)$ \\
\hline Height (cm) & $95.5(3.7)$ & $102.9(4.0)$ & $110.0(4.4)$ & $115.9(4.8)$ & $122.1(5.2)$ \\
\hline Height z score & $0.17(0.94)$ & $0.31(0.94)$ & $0.35(0.93)$ & $0.17(0.94)$ & $0.08(0.95)$ \\
\hline Weight (kg) & 15.7 (1.9) & $17.8(2.2)$ & $20.0(2.5)$ & $22.2(2.9)$ & $25.0(3.7)$ \\
\hline Weight z score & $0.73(0.93)$ & $0.70(0.88)$ & $0.57(0.82)$ & $0.43(0.84)$ & $0.41(0.87)$ \\
\hline BMI & $17.1(1.3)$ & $16.8(1.3)$ & $16.5(1.4)$ & $16.5(1.5)$ & $16.7(1.8)$ \\
\hline BMI z score & $0.87(0.85)$ & $0.87(0.84)$ & $0.72(0.79)$ & $0.62(0.73)$ & $0.56(0.74)$ \\
\hline
\end{tabular}

were standardised to have a mean of 0 and a standard deviation of 1 before combination.

Longitudinal analyses - We used multiple regression models to examine the association between BMI, fat mass index, and fat free mass index at age 7 and the average of the sleep measures from age 3 to 5 . The models included the same variables used in the cross sectional analyses described above, except for the "within person" variables. We used models that excluded or included measures of BMI, fat mass index, and fat free mass index at age 3. This enabled the examination of the effect of sleep on BMI at age 7 (when BMI at age 3 was excluded) and change in BMI from age 3 to 7 (when BMI at age 3 was included).

Software-Data were analysed with STATA 11.1 (Stata Corporation 2010, College Station, TX). The residuals were examined to assess the fit of the models.

\section{RESULTS}

Table 1 presents the characteristics of the study sample at each measurement point. Retention was good, with $83 \%$ of participants seen at age 7 . The remaining participants either left town or did not want to continue to take part. Mean BMI z score declined over time, and fewer children were classified as overweight (BMI $\geq 85$ th centile) at age 7 than at age $3(40 \% v 28 \%$ in girls $(\mathrm{P}<0.001)$ and $42 \%$ v $22 \%$ in boys $(\mathrm{P}<0.001)$ ). Children who were present at follow-up $(\mathrm{n}=202)$ and children who had dropped out $(\mathrm{n}=42)$, however, did not differ in BMI z score (0.88 (SD 0.91) v 0.86 (SD 0.83), $\mathrm{P}=0.886$ ) or sex distribution ( $43 \%$ boys $v 49 \%$ girls, $\mathrm{P}=0.279$ ) at baseline.

Mean sleep duration was about 11 hours a day at all three ages (table 2). As expected, the reported time in bed was greater than the duration of sleep measured objectively by accelerometry by a mean difference of 21 minutes (95\% confidence interval 15 to 28 ) at age 3 , 19 (14 to 24$)$ minutes at age 4 , and 19 (16 to 23 ) minutes at age 5. At age 3, 131 (57\%) children had at least one daytime nap during the five days of monitoring, falling to $34(16 \%)$ children at age 4 and none at age 5 . No difference was seen in total sleep duration between those who did or did not nap at either age $(\mathrm{P}=0.24$ at age 3 and $\mathrm{P}=0.68$ at age 4$)$. The intraclass correlation for repeated measures of sleep (accelerometry) was $0.36(0.27$ to 0.45$)$, resulting in a reliability of 0.60 for the mean of the three sleep measures.

\section{Cross sectional analyses}

Table 3 presents the models for the cross sectional association between sleep and BMI for both univariate and multivariate models. We have not presented the estimates for the "within person" component for sleep and the other measures as they were small and not significant. In the univariate analyses, maternal BMI, ethnicity, smoking during pregnancy, and the intake of non-core foods were all positively associated with BMI. In particular, being of Maori descent and maternal smoking during pregnancy were associated with large differences in BMI from age 3 to 5 (0.89 and 1.22 , respectively). Each additional hour of sleep was associated with a $0.38(0.07$ to 0.70$)$ reduction in BMI. Adjustment for maternal and birth factors (model 2) did not substantially change the estimate $(-0.37)$. Further adjustment for dietary intake and physical activity and inactivity, however, weakened the relation between sleep and BMI $(-0.25,-0.56$ to 0.06$)$.

\section{Longitudinal analyses}

Table 4 presents the models for the longitudinal association between sleep and BMI at age 7 . Data are presented with and without BMI at age 3 to examine the effect of sleep from age 3 to 5 on BMI at age 7 and in change in BMI from age 3 to 7. Associations were similar to those seen in the cross sectional univariate models, with the addition of maternal education as a strong negative predictor of BMI at age 7. A difference of one hour's sleep per night between ages 3 and 5 was associated with a $0.56(0.07$ to 1.06$)$ reduction in BMI. The difference in BMI after adjustment for birth and maternal factors was negligible $(-0.49,-0.97$ to -0.02$)$. Further adjustment for diet and activity did not change the estimate $(-0.48)$ but produced wider confidence intervals $(-0.96$ to 0.01$)$, resulting in a non-significant

Table $2 \mid$ Mean (SD) sleep and physical activity in children at ages 3,4 , and 5

\begin{tabular}{llll} 
& \multicolumn{3}{c}{ Age (years) } \\
\cline { 2 - 4 } & $\mathbf{3 ( n = 2 2 9 )}$ & $\mathbf{4}(\mathrm{n}=\mathbf{2 0 6})$ & $\mathbf{5}(\mathrm{n}=198)$ \\
Time in bed* (hours) & $11.4(0.7)$ & $11.3(0.7)$ & $11.4(0.6)$ \\
\hline Sleep (hours/day) $\dagger$ & $11.1(0.7)$ & $11.0(0.6)$ & $11.1(0.6)$ \\
\hline $\begin{array}{l}\text { Average accelerometry } \\
\text { counts/min } \dagger\end{array}$ & $467(146)$ & $293(116)$ & $284(126)$ \\
\hline *Data obtained from questionnaire. \\
†Data obtained from accelerometry.
\end{tabular}


Table 3|Models for cross sectional association between body mass index (BMI) and sleep at ages 3, 4 and 5. Figures are estimates for change in BMI associated with 1 unit change in independent variables (univariate model) and adjusted for other variables (multivariate models)

\begin{tabular}{|c|c|c|c|c|}
\hline & Univariate model & Multivariate model 1 & Multivariate model 2 & Multivariate model 3 \\
\hline Age (years) & $-0.11(-0.16 \text { to }-0.08)^{*}$ & $-0.32(-0.38 \text { to }-0.27)^{*}$ & $-0.33(-0.38 \text { to }-0.27)^{*}$ & $-0.33(-0.39 \text { to }-0.28)^{\star}$ \\
\hline Sex (male) & $0.24(-0.08$ to 0.57$)$ & $0.13(-0.21$ to 0.46$)$ & $0.07(-0.25$ to 0.38$)$ & $0.04(-0.28$ to 0.37$)$ \\
\hline Maternal education (high) & $-0.18(-0.51$ to 0.16$)$ & - & $-0.00(-0.34$ to 0.33$)$ & $-0.03(-0.38$ to 0.32$)$ \\
\hline Maternal BMI & $0.03(0.00 \text { to } 0.06)^{\star}$ & - & $0.03(-0.00$ to 0.06$)$ & $0.03(-0.00$ to 0.05$)$ \\
\hline Income (6 categories) & $-0.10(-0.21$ to 0.00$)$ & - & $-0.04(-0.15$ to 0.07$)$ & $0.03(-0.14$ to 0.08$)$ \\
\hline Ethnicity (Maori) $†$ & $1.22(0.72 \text { to } 1.73)^{\star}$ & - & $0.97(0.46 \text { to } 1.47)^{\star}$ & $0.95(0.44 \text { to } 1.45)^{*}$ \\
\hline Ethnicity (Pacific)† & $0.16(-0.68$ to 0.99$)$ & - & $-0.47(-1.34$ to 0.39$)$ & $-0.43(-1.32$ to 0.47$)$ \\
\hline Birth weight (kg) & $0.12(-0.23$ to 0.47$)$ & - & $0.32(-0.03$ to 0.67$)$ & $0.32(-0.04$ to 0.68$)$ \\
\hline Smoking during pregnancy (yes) & $0.89(0.50 \text { to } 1.28)^{\star}$ & - & $0.82(0.41 \text { to } 1.23)^{\star}$ & $0.79(0.38 \text { to } 1.21)^{\star}$ \\
\hline Physical activity (1 SD counts/min) & $0.06(-0.16$ to 0.28$)$ & - & - & $-0.02(-0.24$ to 0.20$)$ \\
\hline TV viewing (hours/day) & $0.21(-0.00$ to 0.43$)$ & - & - & $0.11(-0.11$ to 0.32$)$ \\
\hline Fruit-vegetable intake (servings/day) & $0.05(-0.08$ to 0.17$)$ & - & - & $0.09(-0.03$ to 0.22$)$ \\
\hline Non-core foods intake (servings/day) & $0.14(0.00 \text { to } 0.29)^{*}$ & - & - & $0.03(-0.11$ to 0.18$)$ \\
\hline Sleep (hours/day) & $-0.38(-0.70 \text { to }-0.07)^{*}$ & $-0.37(-0.69 \text { to }-0.05)^{*}$ & $-0.24(-0.55$ to 0.10$)$ & $-0.25(-0.56$ to 0.06$)$ \\
\hline
\end{tabular}

effect of sleep on BMI at age $7(\mathrm{P}=0.053)$. Table 4 further shows that for each additional hour of sleep, change in BMI from age 3 to 7 is reduced by 0.39 (0.06 to 0.72$)$.

Greater amounts of sleep also significantly influenced the risk of being overweight (BMI $\geq 85$ th centile $^{27}$ at age 7; each additional hour of sleep reduced the risk of being overweight by 0.39 (0.24 to 0.63), after adjustment for the same confounders as used in table 4 . Addition of the presence of overweight at age 3 made little difference to the reduced risk $(0.44$, 0.29 to 0.67$)$.

Table 5 shows the associations between fat mass index and fat free mass index and sleep, again with both indexes at age 3 included and excluded from the models. Each additional hour of sleep reduced the adjusted fat mass index by 0.43 ( 0.03 to 0.82 ; model 1) at age 7 and by $0.48(0.10$ to 0.86$)$ for the change from age 3 to 7 (model 2). Maternal education was negatively associated with higher fat mass index at age 7 , and birth weight and smoking during pregnancy positively associated. Although more sleep was associated with a considerably smaller reduction in fat free mass index, this relation was not apparent once we adjusted for fat free mass index at age 3 .

\section{DISCUSSION}

Young children who sleep less have a significantly increased risk of having a higher BMI in middle childhood, even after adjustment for multiple risk factors that have been implicated in regulation of body weight. Each additional hour of sleep per night at ages 3 to 5 is associated with a reduction in BMI of 0.49 at age 7 . In a child of median height, this corresponds to a difference of $0.7 \mathrm{~kg}$ body weight. ${ }^{27}$ While this might seem minor at an individual level, the benefits for public health, if applied at the population level are considerable. ${ }^{36} \mathrm{~A}$ shift in the population distribution for BMI implies a reduction in the occurrence of the extreme values or the prevalence of overweight. Our study shows a $61 \%$ reduction in the risk of being overweight or obese at age 7 for each extra hour of sleep. Perhaps more importantly, these differences in body weight are explained by an increased deposition of fat mass, with little difference in fat free mass between children with varying amounts of sleep.

\section{Strengths and limitations}

The strengths of our study include the reasonable retention rates over time, the objective measurement of sleep and physical activity on multiple days by using accelerometry, obtaining repeated measures of major variables including sleep at each time point, and adjustment for multiple confounders. We could not find any other prospective studies that used actigraphy to estimate sleep duration, despite concerns that parental estimates of sleep time obtained by questionnaire might be less accurate in older children than in infants and toddlers. ${ }^{37}$ Use of self reports (or parental proxy for children) of sleep duration can be further complicated by the observation that they might be systematically biased with regard to important confounders for obesity. ${ }^{10}$ The reliability and stability of estimates of sleep is also an issue. ${ }^{38}$ Estimates of reliability for one day of measurement are only 0.21-0.51 in children aged 3-5 but increase to acceptable levels with five days of measurement, ${ }^{39}$ as shown by our study. How stable estimates of sleep are over time in growing children is also not well understood, but measures should not be assumed to be stable on the basis of adult data. ${ }^{10}$ Others report a correlation of $r=0.53$ in 9 year old children followed up two years later, ${ }^{40}$ which is higher than we observed $(r=0.30, \mathrm{P}<0.001)$. The reliability of actigraphy measures of sleep, however, seem to be lower in 3 year olds compared with older children. ${ }^{39}$ Thus studies that obtain a single estimate of sleep time, 
Table $4 \mid$ Models for longitudinal association between body mass index (BMI) at age 7 and sleep and physical activity averaged over ages 3, 4, and 5 . Figures are estimates for change in BMI associated with 1 unit change in independent variables (univariate model) and adjusted for all other variables (multivariate models).

\begin{tabular}{|c|c|c|c|c|}
\hline & Univariate model & Multivariate model 1 & Multivariate model 2 & Multivariate model 3 \\
\hline BMI at age 3 & $0.99(0.86 \text { to } 1.12)^{*}$ & - & - & $0.94(0.81 \text { to } 1.07)^{*}$ \\
\hline Sex (male) & $-0.40(-0.89$ to 0.09$)$ & $-0.53(-0.99 \text { to }-0.07)^{*}$ & $-0.55(-1.01 \text { to }-0.08)^{\star}$ & $-0.75(-1.08 \text { to }-0.44)^{\star}$ \\
\hline Maternal education (high) & $-0.52(-1.02 \text { to }-0.02)^{\star}$ & $-0.27(-0.78$ to 0.23$)$ & $-0.28(-0.80$ to 0.25$)$ & $-0.17(-0.53$ to 0.18$)$ \\
\hline Maternal BMI & $0.06(0.02 \text { to } 0.11)^{\star}$ & $0.05(0.00 \text { to } 0.09)^{*}$ & $0.05(0.01 \text { to } 0.09)^{*}$ & $0.03(0.00 \text { to } 0.06)^{*}$ \\
\hline Income (6 categories) & $-0.10(-0.26$ to 0.06$)$ & $0.00(-0.16$ to 0.16$)$ & $0.02(-0.15$ to 0.19$)$ & $0.00(-0.11$ to 0.12$)$ \\
\hline Ethnicity (Maori)† & $1.51(0.71 \text { to } 2.31)^{\star}$ & $1.27(0.50 \text { to } 2.04)^{\star}$ & $1.23(0.45 \text { to } 2.02)^{*}$ & $0.45(-0.10$ to 1.00$)$ \\
\hline Ethnicity (Pacific) $†$ & $0.43(-0.91$ to 1.77$)$ & $-0.75(-2.08$ to 0.58$)$ & $-0.88(-2.25$ to 0.49$)$ & $-0.33(-1.27$ to 0.62$)$ \\
\hline Birth weight (kg) & $0.39(-0.15$ to 0.93$)$ & $0.68(0.15 \text { to } 1.22)^{\star}$ & $0.68(0.13 \text { to } 1.22)^{*}$ & $0.32(-0.05$ to 0.70$)$ \\
\hline Smoking during pregnancy (yes) & $1.12(0.51 \text { to } 1.72)^{\star}$ & $0.91(0.28 \text { to } 1.54)^{\star}$ & $0.88(0.25 \text { to } 1.52)^{*}$ & $0.17(-0.27$ to 0.62$)$ \\
\hline Physical activity (1 SD counts/min) & $0.22(-0.12$ to 0.55$)$ & - & $0.06(-0.27$ to 0.38$)$ & $0.12(-0.11$ to 0.34$)$ \\
\hline TV viewing (hours/day) & $0.29(-0.03$ to 0.61$)$ & - & $0.16(-0.16$ to 0.48$)$ & $0.01(-0.21$ to 0.22$)$ \\
\hline Fruit-vegetable intake (servings/day) & $-0.04(-0.23$ to 0.14$)$ & - & $0.06(-0.12$ to 0.24$)$ & $-0.03(-0.15$ to 0.09$)$ \\
\hline Non-core foods intake (servings/day) & $0.19(-0.03$ to 0.41$)$ & - & $0.05(-0.17$ to 0.27$)$ & $-0.00(-0.15$ to 0.15$)$ \\
\hline Sleep (hours/day) & $-0.56(-1.06 \text { to }-0.07)^{\star}$ & $-0.49(-0.97 \text { to }-0.02)^{*}$ & $-0.48(-0.96$ to 0.01$)$ & $-0.39(-0.72 \text { to }-0.06)^{\star}$ \\
\hline
\end{tabular}

even if prospectively based, might yield biased estimates. The limitations of our study include the relatively small sample size and perhaps our placement of the accelerometers. Assessment of sleep-wake patterns with accelerometry typically uses the wrist (or ankle in infants) as the measurement site, ${ }^{41}$ whereas placement on the hip is recommended for assessing physical activity. ${ }^{42}$ Use of these two sites can produce different estimates of physical activity. ${ }^{42}{ }^{43}$ We do not think that this impacts on our data, however, given that the trunk remained the sole measurement site throughout the study. Furthermore, it has also been shown that placement at the trunk provides similar detection of sleep-wake patterns as wrist actigraphy and might even reduce the motion artefacts associated with using the wrist as the measurement site for sleep. ${ }^{44}$

\section{Comparison with other studies}

Our BMI findings are broadly concordant with the literature in terms of the magnitude of differences between children with varying sleeping patterns, though direct comparisons are difficult given the mixed ages studied and the different methods of analysis. Estimates have ranged from a difference of 0.16 BMI $\mathrm{z}$ score units at age $3^{17}$ to differences of 0.75 between groups in children aged $8-15 .{ }^{16}$ These differences in BMI extend into adult life; for every hour less sleep at ages 5-11, BMI was 0.93 higher at age $32 .{ }^{19}$ Several longitudinal studies have also reported a reduced risk of overweight or obesity in children with greater sleep duration (relative risk $0.65-0.80)^{1519}$ or conversely a greater odds of being overweight with reduced sleep (odds ratio 1.5-2.0)..$^{1417}$

Our longitudinal study examined differences in body composition according to sleep duration during growth periods. Three cross sectional studies ${ }^{172224}$ have shown that children with less sleep have a higher proportion of body fat, though estimates were obtained with only a minimal number of skinfold thicknesses, presented either as raw data ${ }^{17}$ or converted to percentage body fat values. ${ }^{224}$ The three cross sectional studies with more accurate measures of body fat have had inconsistent findings. ${ }^{212345}$ Although Hitze et al observed no effect of sleep on the risk of having high body fat, ${ }^{23}$ and $\mathrm{Yu}$ et $\mathrm{al}^{21}$ reported minimal effects in females only, others ${ }^{45}$ have shown markedly reduced odds ratios $(0.42,0.24$ to 0.76$)$ with a difference in sleeping of at least 90 minutes a night in a much larger sample. These discrepancies in findings might be at least partly attributable to age. The latter study was undertaken in young children, ${ }^{45}$ for whom the relations between sleep and body weight seem to be more consistent. ${ }^{810}$ Our study shows that children who sleep less gain significantly more fat mass over time, with little difference in lean mass deposition. These differences remain even after adjustment for multiple determinants of body composition during growth.

\section{Proposed mechanisms}

Proposed mechanisms explaining the obesogenic effect of shortened sleep include behavioural and hormonal factors. Reduced sleep might increase dietary intake purely through increased eating in the absence of hunger, particularly snacking, or because of more time being available to eat, ${ }^{46}$ or alternatively, via more complex hormonal regulation. Experimental studies have shown that sleep deprivation decreases leptin and increases ghrelin concentrations, with concomitant increases in appetite. ${ }^{947}$ Sleep deprivation can also influence energy expenditure, through fatigue leading to reduced voluntary exercise or perhaps by influencing thermoregulation. ${ }^{46}$

\section{Unanswered questions and future research}

In conclusion, it seems that sleep is an important determinant of future body composition in young children. 
Table 5|Models for longitudinal association between fat mass index (FMI) or fat free mass index (FFMI) at age 7 and sleep and physical activity averaged over ages 3, 4, and 5. Figures are estimates for change in FMI and FFMI associated with 1 unit change in independent variables (univariate model) and adjusted for all other variables (multivariate models)

\begin{tabular}{|c|c|c|c|c|}
\hline & \multicolumn{2}{|c|}{ Change in FMI } & \multicolumn{2}{|c|}{ Change in FFMI } \\
\hline & Multivariate model 1 & Multivariate model 2 & Multivariate model 1 & Multivariate model 2 \\
\hline FMI or FFMI at age 3 & - & $0.46(0.24 \text { to } 0.68)^{*}$ & - & $0.42(0.31$ to 0.52$)$ \\
\hline Sex (male) & $-0.92(-1.32 \text { to }-0.51)^{*}$ & $-0.36(-0.83$ to 0.12$)$ & $0.33(0.12 \text { to } 0.54)^{\star}$ & $-0.25(-0.49 \text { to }-0.00)^{*}$ \\
\hline Maternal education (high) & $-0.63(-1.06 \text { to }-0.18)^{*}$ & $-0.61(-1.03 \text { to }-0.18)^{\star}$ & $0.06(-0.17$ to 0.28$)$ & $0.07(-0.13$ to 0.27$)$ \\
\hline Maternal BMI & $0.00(-0.03$ to 0.04$)$ & $-0.00(-0.04$ to 0.03$)$ & $0.02(0.00 \text { to } 0.04)^{\star}$ & $0.02(0.00 \text { to } 0.03)^{\star}$ \\
\hline Income (6 categories) & $0.09(-0.05$ to 0.23$)$ & $0.11(-0.03$ to 0.24$)$ & $0.05(-0.02$ to 0.12$)$ & $0.06(-0.01$ to 0.12$)$ \\
\hline Ethnicity (Maori) & $0.51(-0.14$ to 1.16$)$ & $0.15(-0.49$ to 0.79$)$ & $0.41(0.08 \text { to } 0.75)^{*}$ & $0.25(-0.05$ to 0.56$)$ \\
\hline Ethnicity (Pacific) & $0.06(-1.07$ to 1.20$)$ & $0.01(-1.08$ to 1.10$)$ & $0.28(-0.31$ to 0.86$)$ & $0.50(-0.02$ to 1.01$)$ \\
\hline Birth weight (kg) & $0.49(0.03 \text { to } 0.95)^{\star}$ & $0.41(-0.03$ to 0.85$)$ & $0.13(-0.10$ to 0.37$)$ & $0.09(-0.12$ to 0.29$)$ \\
\hline Smoking during pregnancy (yes) & $0.62(0.10 \text { to } 1.16)^{*}$ & $0.48(-0.04$ to 0.99$)$ & $0.24(-0.03$ to 0.52$)$ & $0.07(-0.18$ to 0.31$)$ \\
\hline Physical activity (1 SD counts/min) & $-0.17(-0.44$ to 0.11$)$ & $-0.12(-0.39$ to 0.15$)$ & $-0.02(-0.16$ to 0.12$)$ & $-0.04(-0.16$ to 0.09$)$ \\
\hline TV viewing (hours/day) & $0.18(-0.09$ to 0.45$)$ & $0.13(-0.14$ to 0.40$)$ & $-0.02(-0.16$ to 0.12$)$ & $-0.02(-0.15$ to 0.11$)$ \\
\hline Fruit-vegetable intake (servings/day) & $0.04(-0.12$ to 0.19$)$ & $0.01(-0.14$ to 0.16$)$ & $0.09(0.01 \text { to } 0.17)^{\star}$ & $0.08(0.00 \text { to } 0.14)^{\star}$ \\
\hline Non-core foods intake (servings/day) & $-0.11(-0.29$ to 0.07$)$ & $-0.09(-0.27$ to 0.09$)$ & $0.02(-0.07$ to 0.12$)$ & $-0.01(-0.09$ to 0.08$)$ \\
\hline Sleep (hours/day) & $-0.43(-0.82 \text { to }-0.03)^{*}$ & $-0.48(-0.86 \text { to }-0.10)^{\star}$ & $-0.21(-0.41 \text { to }-0.00)^{*}$ & $-0.11(-0.29$ to 0.07$)$ \\
\hline
\end{tabular}

${ }^{\star} \mathrm{P}<0.05$.

†Reference group was New Zealand European and others.

Youngsters who sleep less are more likely to be overweight, with high body fat values, even after adjustment for lifestyle variables that can also influence body weight. The temporal relation between sleep and later body weight suggests that the association is causal, though, in common with all naturalistic studies, unrecognised or non-observed sources of confounding might not have been taken into account. Nevertheless, appropriate sleep habits should be encouraged in all children as an appropriate public health measure. Targets for appropriate hours of sleep for children of different ages have been suggested and could be used as a starting point for interacting with children and their parents. ${ }^{48}$ Whether changes in sleep habits have the ability to causally affect body weight remains to be seen, ${ }^{10}$ but it is a topic of immense interest. Future interventions are needed to determine whether more sleep or better sleeping patterns impact favourably on body weight and other health outcomes.

\section{WHAT IS ALREADY KNOWN ON THIS TOPIC}

Although reduced sleep has been consistently associated with higher body weight in children, current longitudinal studies have been limited by not having repeated objective measures of sleep or physical activity, and adjustment for confounding variables has been mixed

No longitudinal studies have determined whether reduced sleep during growth is associated with changes in the deposition of fat mass and fat free mass

\section{WHAT THIS STUDY ADDS}

The relation between reduced sleep and greater subsequent BMI remains strong even after adjustment for multiple confounders (physical activity/inactivity, diet, birth weight, and maternal factors including BMI, education, and smoking during pregnancy)

This higher BMI is because of a greater deposition of body fat rather than differences in the accumulation of fat free mass
Contributors: PJC was involved in initial design of the longitudinal study, undertook the data collection, completed all accelerometry analyses, produced the initial methods section of the paper, and revised the draft paper. BJT was the principal investigator of the project and was responsible for study design, monitoring of data collection, and revision of the draft paper. SWM contributed to study design, designed and completed all statistical analyses, and revised the draft paper. RWT conceived the idea for this paper, was involved in study design, monitored data collection, drafted and revised the paper, and is guarantor

Funding: This study was funded by the University of Otago, the Child Health Research Foundation, the New Zealand Heart Foundation, and the Dean's Bequest-AAW Jones Trust. The funders had no role in study design; or in the collection, analysis, and interpretation of data; or in the writing of the report or the decision to submit the article for publication. Competing interests: All authors have completed the Unified Competing Interest form at www.icmje.org/coi_disclosure.pdf (available on request from the corresponding author) and declare: no support from any organisation for the submitted work; no financial relationships with any organisations that might have an interest in the submitted work in the previous three years; no other relationships or activities that could appear to have influenced the submitted work.

Ethical approval: The study was approved by the Lower South regional ethics committee (Reference OTA/04/03/023) and signed informed consent was obtained from the parents or guardians of each participating child.

Data sharing: No additional data available.

1 Sundblom E, Petzold M, Rasmussen F, Callmer E, Lissner L. Childhood overweight and obesity prevalences levelling off in Stockholm but socioeconomic differences persist. Int J Obes 2008;32:1525-30.

2 Ministry of Health, New Zealand. A portrait of health: key results of the 2006/07 New Zealand health survey. Ministry of Health, 2008.

3 Ogden CL, Carrol MD, Curtin LR, Lamb MM, Flegal KM. Prevalence of high body mass index in US children and adolescents, 2007-2008. JAMA 2010;303:242-9.

4 Iglowstein I, Jenni OG, Molinari L, Largo RH. Sleep duration from infancy to adolescence: reference values and generational trends. Pediatrics 2003;111:302-7.

5 Dollman J, Ridley K, Olds T, Lowe E. Trends in the duration of schoolday sleep among 10- to 15-year-old South Australians between 1985 and 2004. Acta Paediatrica 2007;96:1011-4.

6 Keith SW, Redden DT, Katzmarzyk PT, Boggiano MM, Hanlon EC, Benca RM, et al. Putative contributors to the secular increase in obesity: exploring the roads less traveled. Int J Obes 2006;30:1585-94 
7 Cappuccio FP, Taggart FM, Kandala NB, Currie A, Peile E, Stranges S, et al. Meta-analysis of short sleep duration and obesity in children and adults. Sleep 2008;31:619-26.

8 Chen X, Beydoun MA, Wang Y. Is sleep duration associated with childhood obesity? A systematic review and meta-analysis. Obesity 2008;16:265-74.

9 Hart CN, Jelalian E. Shortened sleep duraton is associated with pediatric overweight. Behav Sleep Med 2008;6:251-67.

10 Marshall NS, Glozier N, Grunstein RR. Is sleep duration related to obesity? A critical review of the epidemiological evidence. Sleep Med Rev 2008;12:289-98.

11 Patel SR, Hu FB. Short sleep duration and weight gain: a systematic review. Obesity 2008;16:643-53.

12 Agras WS, Hammer LD, McNicholas F, Kraemer HC. Risk factors for childhood overweight: a prospective study from birth to 9.5 years. I Pediatr 2004;145:20-5.

13 Sugimori H, Yoshida K, Izuno T, Miyakawa M, Suka M, Sekine M, et al. Analysis of factors that influence body mass index from ages 3 to 6 years: a study based on the Toyama cohort study. Pediatr Int 2004;46:302-10.

14 Reilly JJ, Armstrong J, Dorosty AR, Emmett PM, Ness A, Rogers I, et al. Early life risk factors for obesity in childhood: cohort study. BMJ 2005;330:1357.

15 Lumeng JC, Somashekar D, Appugliese D, Kaciroti N, Corwyn RF, Bradley $\mathrm{RH}$. Shorter sleep duration is associated with increased risk for being overweight at ages 9 to 12 years. Pediatrics 2007;120:1020-9.

16 Snell EK, Adam EK, Duncan GJ. Sleep and the body mass index and overweight status of children and adolescents. Child Dev 2007;78:309-23.

17 Taveras EM, Rifas-Shiman SL, Oken E, Gunderson EP, Gillman MW. Short sleep duration in infancy and risk of childhood overweight. Arch Pediatr Adolesc Med 2008;162:305-11.

18 Touchette E, Petit D, Tremblay RE, Boivin M, Falissard B, Genolini C, et al. Associations between sleep duration patterns and overweight/ obesity at age 6. Sleep 2008;31:1507-14.

19 Landhuis CE, Poulton R, Welch D, Hancox RJ. Childhood sleep time and long-term risk for obesity: a 32-year prospective birth cohort study. Pediatrics 2008;122:955-60.

20 Must A, Parisi SM. Sedentary behaviour and sleep: paradoxical effects in association with childhood obesity. Int J Obes 2009;33:S82-6.

21 Yu X, Lu BS, Wang B, Wang H, Yang J, Li Z, et al. Short sleep duration and adiposity in Chinese adolescents. Sleep 2007;30:1688-97.

22 Bayer O, Rosario AS, Wabitsch M, von Kries R. Sleep duration and obesity in children: is the association dependent on age and choice of outcome parameter? Sleep 2009;32:1183-9.

23 Hitze B, Bosy-Westphal A, Bielfeldt F, Settler U, Plachta-Danielzik S, Pfeuffer M, et al. Determinants and impact of sleep duration in children and adolescents: data of the Kiel Obesity Prevention Study. Eur J Clin Nutr 2009;63:739-46.

24 Padez C, Mourao I, Moreira P, Rosado V. Long sleep duration and childhood overweight/obesity and body fat. Am J Hum Biol 2009;21:371-6.

25 Wells JCK, Fuller NJ, Dewit O, Fewtrell MS, Elia M, Cole TJ. Fourcomponent model of body composition in children: density and hydration of fat-free mass and comparison with simpler models. Am J Clin Nutr 1999;69:904-12.

26 Taylor RW, Murdoch L, Carter P, Gerrard DF, Williams SM, Taylor BJ. Longitudinal study of physical activity and inactivity in preschoolers: FLAME study. Med Sci Sports Exerc 2009;41:96-102.

27 Kuczmarski RJ, Ogden CL, Guo SS, Grummer-Strawn LM, Flegal KM, Mei Z, et al. 2000 CDC growth charts for the United States: methods and development. Data from the National Health Survey. Vital Health Stat 11 2002;246:1-190.
28 Horlick M, Arpadi SM, Bethel J, Wang J, Moye J Jr, Cuff P, et al. Bioelectrical impedance analysis models for prediction of total body water and fat-free mass in healthy and HIV-infected children and adolescents. Am J Clin Nutr 2002;76:991-9.

29 Roche AF, Heymsfield SB, Lohman TG. Human body composition. Human Kinetics, 1996.

30 Taylor RW, Jones IE, Williams S, Goulding A. DXA body fat percentages corresponding to recently recommended body mass index cut-offs denoting overweight and obesity in children and adolescents aged 3 to 18 years. Am J Clin Nutr 2002;76:1416-21.

31 Pfeiffer KA, Mclver KL, Dowda M, Almeida MJCA, Pate RR. Validation and calibration of the actical accelerometer in preschool children. Med Sci Sports Exerc 2006;38:152-7.

32 Puyau MR, Adolph AL, Vohra FA, Zakeri I, Butte NF. Prediction of activity energy expenditure using accelerometers in children. Med Sci Sports Exerc 2004;36:1625-31.

33 Littner M, Kushida CA, Anderson WM, Bailey D, Berry RB, Davila DG, et al. Practice parameters for the role of actigraphy in the study of sleep and circadian rhythms: an update for 2002. Sleep 2003;26:337-41.

34 Taylor RW, McAuley KA, Barbezat W, Strong A, Williams SM, Mann JI. APPLE project: 2-y findings of a community-based obesity prevention program in primary school-age children. Am J Clin Nutr 2007;86:735-42.

35 Fitzmaurice GM, Laird NM, Ware JH. Applied longitudinal analysis. John Wiley, 2004.

36 Rose G. The strategy of preventive medicine. Oxford University Press, 1992.

37 Nixon GM, Thompson JMD, Han DY, Becroft DM, Clark PM, Robinson E, et al. Short sleep duration in middle childhood: risk factors and consequences. Sleep 2008;31:71-8.

38 Sadeh A, Acebo C. The role of actigraphy in sleep medicine. Sleep Med Rev 2002;6:113-4.

39 Acebo C, Sadeh A, Seifer R, Tzischinsky O, Wolfson AR, Hafer A, et al. Estimating sleep patterns with activity monitoring in children and adolescents: how many nights are necessary for reliable measures? Sleep 1999;22:95-103.

40 Sadeh A, Dahl RE, Shahar G, Rosenblat-Stein S. Sleep and the transition to adolescence: a longitudinal study. Sleep 2009;32:1602-9.

41 Sadeh A. Commentary: comparing actigraphy and parental report as measures of children's sleep. J Pediatr Psychol 2009;33:406-7.

42 Cliff DP, Reilly JJ, Okely AD. Methodological considerations in using accelerometers to assess habitual physical activity in children aged 0-5 years. I Sci Med Sport 2009;12:557-67.

43 Swartz AM, Strath SJ, Bassett DR, O’Brien WL, King GA, Ainsworth BE. Estimation of energy expenditure using CSA accelerometers at hip and wrist sites. Med Sci Sports Exerc 2000;32:S450-6.

44 Sazonov E, Sazonova N, Schuckers S, Neuman M, and the CHIME Study Group. Activity-based sleep-wake identification in infants. Physiol Meas 2004;25:1291-304.

45 Von Kries R, Toschke AM, Wurmser H, Sauerwald T, Koletzko B. Reduced risk for overweight and obesity in 5- and 6-yr-old children by duration of sleep-a cross-sectional study. Int J Obes 2002;26:710-6

46 Patel SR. Reduced sleep as an obesity risk factor. Obes Rev 2009;10(suppl 2):61-8.

47 Gangwisch JE. Epidemiological evidence for the links between sleep, circadian rhythms and metabolism. Obes Rev 2009;10(suppl 2):37-45.

48 McLaughlin Crabtree V, Williams NA. Normal sleep in children and adolescents. Child Adolesc Psychiatr Clin N Am 2009;18:799-811.

Accepted: 17 March 2011 